\title{
ATITUDE: ATRIBUTO À COMPETÊNCIA
}

\author{
Júlio Cesar Schmitt Rocha
}

Universidade Federal de Santa Catarina, Florianópolis, Santa Catarina, Brasil

Juarez Vieira do Nascimento

Universidade Federal de Santa Catarina, Florianópolis, Santa Catarina, Brasil

\begin{abstract}
Resumo
O objetivo do presente ensaio foi ampliar a compreensão sobre a competência no campo educacional a partir do papel qualificador exercido pela dimensão da atitude. Ao longo do percurso deste estudo defendeu-se que as competências são uma construção social, portanto, não são neutras. Apresentaram-se as bases teórico-conceituais que sustentam as competências e suas implicações na organização curricular, destacando-se as qualidades pessoais como alicerce da mobilização dos saberes. Firmou-se o papel qualificador da atitude como atributo à competência e balizador da ação educacional, a fim de alcançar uma conjunção mais harmônica e integral ao longo da formação.
\end{abstract}

Palavras chave: Atitude. Competência. Formação.

\section{Introdução}

O termo competência tem provocado, com determinada frequência, incertezas e controvérsias frente às intencionalidades que tenta objetivar no campo educacional. De fato, a sua definição tem sido apreendida por meio da evolução das tendências educativas e de pesquisas que buscam, em seu referencial, esclarecer os diversos sentidos a este termo atribuídos (DOLZ; OLLAGNIER, 2004).

A raiz etimológica da palavra competência revela sua origem do verbo latino competere: "com" significa juntos, e "petere" significa procurar, buscar, convergir (FERREIRA, 2009). Ao aproximar tais significados percebe-se a sua adequabilidade para o contexto educacional, pois é inadmissível que nesse ambiente seus integrantes não busquem ou atuem coletivamente por um mesmo fim. De competere derivam também o verbo 'competir', o adjetivo 'competente' e o substantivo 'competição'.

Na literatura há relatos vinculando formação profissional às competências desde os anos de 1920 numa concreta aliança entre desenvolvimento industrial e formação profissional. Mas é sob a influência da psicologia be- 
haviorista, sedimentada nos anos de 1950, que se sucederam as reformas curriculares sustentadas por objetivos comportamentalistas de aprendizagem (as pedagogias por objetivos) e as reformas dos programas de formação de professores baseados na aquisição de competências, entendidas como comportamentos observáveis. Prevalecia até os anos 1980 o pensamento de que competência era o comportamento observável, confundindo competência e performance (ESTEVES, 2009).

Burgoyne (1988) defende a ideia de que "ser competente" é muito diferente de "ter competências", pois ser competente implica cumprir as exigências impostas pelo trabalho, enquanto possuir competências não leva necessariamente a um desempenho adequado às exigências do trabalho. Não basta, portanto, deter qualidades adequadas para ser considerado competente: é necessário saber mobilizá-las em situações concretas. Além do mais, cada desempenho específico depende de vários fatores para avaliá-lo como exitoso.

Esteves (2009) diferencia o conceito no singular e no plural. Enquanto "a competência" compreende a qualidade que permite separar os profissionais mais competentes dos menos competentes, um traço global de ação do indivíduo ou do grupo profissional que possibilita emitir um juízo de valor; "as competências" remetem a determinados traços evidenciáveis na ação, observados e descritos sem que necessariamente seja imperioso atribuir-lhes um valor. Assim, usar a competência no sentido global, ou as competências, em sentido analítico ou particular, faz muita diferença em termos conceituais.

Dentre as afirmações mais utilizadas nas definições de competência no meio educativo, Allal (2004, p. 83) salienta que uma competência compreende diversos conhecimentos relacionados; que se aplica a uma família de situações; e que é orientada para uma finalidade. Ao conceber competência como "uma rede integrada e funcional constituída por componentes cognitivos, afetivos, sociais, sensório-motores, capaz de ser mobilizada em ações finalizadas diante de uma família de situações", Allal (2004) ensina que a noção de rede implica ligação funcional desses componentes, organizando as atividades dos sujeitos, e que, por sua condição de ser mobilizada, preserva a distinção importante entre competência e desempenho. Isso porque, mesmo com competência confirmada, há circunstâncias em que o sujeito não poderá manifestá-las.

Em diversas áreas de formação, Esteves (2009) apresenta a utilização de um conjunto de competências genéricas ou globais extraídas de profissionais excelentes que determinam o seu sucesso. Portanto, nesse meio, indica tais competências genéricas como mais significativas do que as numerosas competências analíticas sistematizadas nas funções laborais. O per-

Pensar a Prática, Goiânia, v. 17, n. 3, p. 878-892, jul./set. 2014 
fil de profissionais competentes na corrente generalista focou os modos como os profissionais se tornam competentes, destacando um conjunto de qualidades pessoais relevantes, além das características científicas e técnicas inerentes à ação.

Neste caminho, compreende-se cada vez mais que a formação retrata no seu fazer diário as forças que nela atuam. Além disso, a perspectiva utilitária e subalterna da competência calcada na mera aprendizagem e desempenho imediato tem sido enfrentada. Para contribuir com este enfrentamento e refletir ante esta limitada concepção busca-se com este ensaio ampliar a compreensão sobre a competência no campo educacional a partir do papel qualificador exercido pela dimensão da atitude.

\section{Competências: matrizes teórico-conceituais}

Na busca pelo desenvolvimento qualitativo das competências é necessário reconhecer, inicialmente, que há sempre aspectos que requerem tomadas de decisões nem sempre comuns. São aspectos que se encontram em reciprocidade e que possibilitam a capacidade de enfrentamento a partir da estruturação e intervenção sustentada pelos conhecimentos qualificadores, o divisar do caminho a seguir e os valores almejados.

No âmbito da formação do educador é crucial situar os conceitos de competência na vertente epistemológica, na qual se sustentam e são orientadas todas as definições para as práticas nela desenvolvidas. Enquanto teoria do conhecimento, a epistemologia é a área que estuda os critérios de verdade das ciências, cuja sistemática filosófica busca explicações de sua origem, seus processos e validade, tanto sob o ponto de vista descritivo como crítico (SEVERINO, 2001).

Ao investigar os processos de identificação e definição de competência e suas implicações na organização curricular, Deluiz (2001) identificou a existência de várias matrizes teórico-conceituais ancoradas em modelos epistemológicos que as fundamentam, nomeadamente a matriz condutivista ou behaviorista; a funcionalista; a construtivista e a crítico-emancipatória.

As matrizes calcadas na abordagem empirista se caracterizam por uma concepção de competência como algo objetivo, um bem dado, cuja verdade deve ser transmitida, repetida e assimilada. Um processo de cadeias cartesianas em que o conhecimento é entendido como descoberta, como resultado direto de experiências. Por outro lado, a matriz sustentada pela abordagem inatista percebe a competência como algo próprio do ser humano, que por sua capacidade interna e inata o credencia a conhecer e interpretar os fenômenos. $\mathrm{O}$ indivíduo não se submete aos estímulos do meio de forma cega e automática, mas da forma como o percebe subjetivamente. A matriz

Pensar a Prática, Goiânia, v. 17, n. 3, p. 878-892, jul./set. 2014 
de abordagem dialética entende a competência como construção permanente, comprometida em reconhecer sua provisoriedade, fruto da interação reinante entre o ser (intersubjetiva) e o mundo, como fenômeno social que se renova constantemente.

Um aspecto a destacar é que a competência, desde a seleção, o reconhecer construtivo da formação e a vivência incorporativa, não se dá e não está restrita a uma única fonte do saber, pois é gestada pela mobilização de várias circunstâncias valorativas, tanto dos indivíduos como da sociedade. Além disso, cada uma das matrizes de competência sustentada pelas teorias do conhecimento dá respaldo a interesses e expectativas que se refletem na organização educativa, por meio de propostas, estratégias em busca de metas sociais. Se os participantes não conseguirem divisar esses condicionantes, mais enredados permanecerão e as condições limitativas do seu agir não afrontarão a hegemonia reinante.

Finalmente, por ser uma construção social, as competências não são neutras. Assim, torna-se necessário que a educação enfrente dinamicamente aquelas que afrontem o limite da integridade pessoal e social de seus participantes. E, ao compreender melhor os contornos conceituais que cercam a educação, possibilita-se a sempre almejada resignificação de sua noção, por utilizá-la no preparo de profissionais que se envolverão na formação de outras pessoas.

\section{Competência: atributos pessoais}

Mobilização de saberes

A perspectiva mais integral da competência, mais voltada ao ser do que à performance (que pode ser facilmente observada), só pode ser constatada a partir de múltiplos desempenhos. Assim, compreende-se que a competência é relacional, porquanto incorpora atributos (características pessoais relevantes como: conhecimento, habilidades e atitudes) e tarefas, resultando essencialmente da relação entre capacidades e potencialidades das pessoas e a conclusão satisfatória de determinada tarefa (BATISTA, 2008).

Para melhor compreender os atributos, são relevantes os estudos de Le Boterf (2003), os quais têm contribuído na investigação sobre as competências. $\mathrm{O}$ autor manifesta seu interesse em estudar as profissões complexas e os tipos de competências que exigem, por entender que é nelas que os profissionais mais devem enfrentar o desconhecido e a mudança permanente (ESTEVES, 2009).

A competência, de acordo com Le Boterf (2003), compreende a mobilização de saberes (saber, saber fazer e qualidades pessoais) num saber 
agir responsável e reconhecido pelos outros. Implica saber como mobilizar, integrar e transferir os saberes num contexto profissional determinado.

Para esse autor, a competência deriva de um saber atuar, que depende do poder e do querer atuar da pessoa. A competência é muito mais do que os recursos em si, ela se constitui por um saber mobilizar - no qual não basta deter os conhecimentos ou capacidades para ser competente, mas pô-los em execução quando for necessário, utilizando-os nas circunstâncias apropriadas; um saber combinar - no qual o profissional deve selecionar os elementos necessários no repertório de fontes que possui, deve organizá-los e empregá-los para realizar a sua atividade profissional; um saber transferir que requer a capacidade de transferir e adaptar, pois toda a competência é transferível e adaptável; um saber fazer aprovado e reconhecido - porque a competência põe o ajuste à prova, necessita de ocorrer, ser real.

Ao buscar a excelência do profissional por meio de competências, a formação docente se enquadra na descrição das profissões complexas de Le Boterf (2003). Vale dizer: a eficácia da formação não se restringe ao cumprimento de instruções dadas, mas reconhece e enfrenta a complexidade de seus problemas, em um contexto dinâmico de atuação, valendo-se das novas possibilidades tecnológicas e das organizações, sem desconsiderar a evolução dos sistemas de valor e das aspirações dos indivíduos nela envolvidos.

A mobilização dos saberes pode ser compreendida com base em noções de complexidade e de dificuldade. Enquanto a complexidade remete às características objetivas de uma situação ou de um problema que se impõe aos sujeitos, a dificuldade se refere às capacidades do sujeito para enfrentar uma situação, relaciona-se com os recursos disponíveis e com sua seleção e mobilização em ações consentâneas com a situação.

Assim, há determinada analogia entre um profissional competente e a pilotagem ou a navegação, ao reconhecer que o profissional deve saber navegar na complexidade. De fato, o ato de navegar se faz muito mais por balizas do que pela execução de um plano rígido. Assim, pouco adianta navegar em linha reta, no piloto automático, enfrentando ventos contrários, porque a cada momento criam-se novas situações que requerem retomada e readequação das iniciativas.

Nesse ideário de navegador, Le Boterf (2003) identifica seis competências inerentes aos profissionais que sabem gerir a complexidade, especificamente: o saber agir e reagir com pertinência; saber combinar recursos e mobilizá-los em um contexto; saber transpor; saber aprender; aprender a aprender e saber envolver-se.

Outro aspecto importante é a necessária disposição em busca da competência pela mobilização do repertório de recursos pessoais. Nesse sentido, os componentes vinculados à esfera do conhecimento, da habilidade $\mathrm{e}$

Pensar a Prática, Goiânia, v. 17, n. 3, p. 878-892, jul./set. 2014 
das atitudes podem ser compreendidos como recursos associados aos saberes (o conhecimento), ao saber fazer (a habilidade), e às qualidades pessoais e aos recursos emocionais (a atitude), entendimento este também adotado por Dacoreggio (2006).

Convém salientar que o conhecimento convive entre diversificados caminhos e há mútua influência exercida pelas teorias do conhecimento e suas bases conceituais. Ele realmente se constrói nas ações e no que delas decorre, envolvendo as múltiplas interações dos sujeitos, entre estes e os objetos e o meio, o que dá sentido ao entendimento associativo acima apresentado.

Quanto às habilidades, embora pareça não haver consenso na literatura consultada sobre sua definição conceitual, de modo geral é possível considerá-las como as capacidades do ser humano em realizar ações que exigem domínio de conhecimento.

No seu trabalho, Batista (2008) constata que os recursos acerca do conhecimento e das habilidades surgem incorporados na grande maioria às noções de competência, e que no nível de formação, principalmente na formação do professor, o conhecimento, em seus variados domínios, é a referência básica de competência.

Para Perrenoud (1999) a competência assume um lugar central no debate da formação no contexto escolar ao compreendê-la como a capacidade de atuar eficazmente em determinada situação apoiada em conhecimentos, mas não se limitando a eles. Embora atribua determinada relevância ao conhecimento e entenda que ele não é suficiente para um agir competente, o autor salienta que os conhecimentos devem estar disponibilizados, em sintonia e adequados ao momento, sendo determinantes para identificar e preparar as decisões e resolver os problemas.

\section{Atitude - papel qualificador}

É pela atitude que se integra a noção de competência, que (re)valoriza as pessoas e seus atributos na vida em sociedade. É com atitude que se resgata o papel qualificador para a formação por competência, reconhecendo-a como integrante obrigatória e contributiva para romper o predomínio da perspectiva comportamental, produtivista e impessoal que lhe é atribuída.

É necessário admitir a reciprocidade contínua dos diversificados saberes e das qualidades pessoais presentes na formação e resgatar o termo educar, que vem do latim educare, tirar de dentro. É preciso reorientar a formação por competência para não se ater predominantemente às determinações do universo externo ligadas ao mundo produtivo e de desempenho uni- 
forme, mas também reconhecer a reciprocidade das atitudes valorativas na significação do saber e do fazer, frente às almejadas contribuições em favor do bem coletivo.

Embora a maioria dos autores consultados incorpore a atitude como um dos componentes que constituem a competência, outros apresentam argumentos que a colocam num nível diferenciado. Batista (2008) apresenta a relevância dos componentes da competência direcionada ao campo da formação ao compará-los a um iceberg, que possui uma parte visível e outra submersa. Os conhecimentos e as habilidades tendem a ser a parte visível, mais susceptível de ser ensinada e se desenvolver com o treinamento. Por outro lado, a parte submersa compreende as atitudes sustentadas pelas características pessoais, como autoconhecimento, emoções e razões valorativas que jazem escondidas, de difícil acesso e maior dificuldade de desenvolvimento.

Da mesma forma, e em concordância com essa visão diferenciada, Matos (1989) defende que a atitude não deve ser considerada um elemento da competência, mas um atributo que a determina.

O trabalho de Krech, Crutchfield e Ballachey (1969, p. 223) contribui para a compreensão de que as atitudes podem variar de uma pessoa para outra e se relacionam aos objetos do seu universo social, político, econômico, estético e religioso, entre outros. Os autores identificam três componentes mutuamente interdependentes: as crenças sobre o objeto - o componente cognitivo; a emoção ligada ao objeto - o componente de sentimento; a disposição para agir diante do objeto - o componente de tendência para a ação. Os mesmos comentam que muitas atitudes refletem os valores individuais e a concepção do que para este é bom ou desejável e finalizam ensinando que "[...] o mesmo valor pode levar diferentes pessoas a desenvolver atitudes diferentes- e mesmo opostas".

O desenvolvimento das atitudes ou sua mudança se dá pela necessidade e pelas informações às quais a pessoa está exposta, influências estas que podem gerar fortes atitudes de rejeição ou de aceitação diante de pessoas, situações e/ou objetos diversos. As influências externas mais frequentes às quais uma pessoa está submetida ocorrem na comunicação, na atualização de conteúdos e no significado destes no contexto. Tais situações são típicas do ambiente formador, onde ação e conhecimento são mediados pelas valorações das relações intersubjetivas (educador/aluno/alunos).

De acordo com Sarabia (2000), com base na percepção do sujeito, uma atitude é formulada sempre como uma propriedade da personalidade, por mais que sua gênese se deva a determinantes sociais, tais como normas, papéis, valores ou crenças, não se distinguindo por completo de outros construtos de personalidade. A atitude é tratada pela psicologia social como um 
construto hipotético, um processo que se supõe existir, por percebê-lo, mesmo quando não for diretamente observável ou mensurável. Assim, a atitude é definida pelas propriedades que lhe são atribuídas.

Ao compreender as atitudes como disposições adquiridas que avaliam objetos, pessoas e acontecimentos e que pautam a atuação por essa avaliação, Sarabia (2000) destaca quatro funções psicológicas, todas de natureza motivacional: A função defensiva atuaria como mecanismo de proteção diante de fatos que nos desagradam; a função adaptativa auxilia no alcance dos objetivos desejados, na maximização de recompensas e na minimização de castigos; a função expressiva dos valores reflete os valores mais relevantes sobre o mundo e sobre si mesmo; e a função cognoscitiva, que ordena e esclarece a atuação, proporcionando estabilidade ao mundo em que se vive.

Reconhecendo as consequências que as atitudes têm sobre as pessoas e no contexto, questiona-se o quanto tais funções em algum momento deixam de estar presentes, ou podem ser ignoradas no processo de formação inicial ao qual o educador/educando está submetido. Acredita-se que a instituição educativa não se limita e nem se limitará a um processo de ensino concentrado somente no conhecimento e nas habilidades, porque os valores e atitudes permeiam todos os seus procedimentos, qualificando-os. De forma explícita ou não, há de se reconhecer a imersão das atitudes no sistema educacional onde se encontram intrínsecas, e uma de suas obrigações é também buscar transmitir, reproduzir e contribuir na geração de atitudes e valores essenciais à vida integral, ratificando seu compromisso social.

\section{A reciprocidade entre atitude, valor e norma}

Os currículos estruturados por competência, que têm obrigação de utilizar de forma recorrente os meios interventivos, devem prestar mais atenção à formação e à mudança de atitudes. Nessas vivências, educadores e educandos se expõem a situações que contribuem para o aprimoramento do saber, do saber fazer e de seus valores - as atitudes - submetendo-as à avaliação social pelas condutas manifestadas.

Assim, as atitudes manifestadas são compreendidas por serem "a forma como cada pessoa realiza sua conduta de acordo com valores determinados". Portanto, nenhuma atitude ocorre sem se sustentar em valores que são entendidos como "princípios ou as ideias éticas que permitem às pessoas emitir um juízo sobre condutas e seu sentido" (ZABALA, 1998, p. 46).

Para Silva (1988), os valores são qualidades ou significações que expressam que os seres não sucumbem à indiferença no processo de relação

Pensar a Prática, Goiânia, v. 17, n. 3, p. 878-892, jul./set. 2014 
entre si, e que eles só têm sentido numa atividade valorativa real, possível e situada.

E é pela atividade educativa concreta, de experiência, o componente de conduta da atitude, que se dá a vivência dos valores pelo esforço valorativo de quem dela participa. Nesse comportamento fundamental do homem, Furter (1972) esclarece que a valoração é sempre uma experiência concreta, por referir-se a determinada situação; é sempre uma experiência vivenciada por um sujeito: indicando sua relação com as testemunhas ou intermediários dos valores; é uma experiência muitas vezes anterior ao próprio ato reflexivo, à tomada de consciência dos valores, representa a possibilidade de descoberta dos valores, no sentido de apreensão ou doação de significados; a experiência axiológica não 'acaba' com a descoberta dos valores (no sentido da tomada de consciência), mas representa uma abertura, um apelo para as novas ações e criações.

Para aprimorar o pensar sobre a importância da atitude na formação e o papel dos valores que a determinam, é oportuno trazer a contribuição de Vazquez (1985, p. 127) ao afirmar que os valores:

[...] não existem em si e por si independentemente dos objetos reais - cujas propriedades objetivas se apresentam então como propriedades valiosas (isto é humanas, sociais) - nem tampouco independentemente da relação com o sujeito (o homem social). Existem assim objetivamente, isto é, com uma objetividade social. Os valores, por conseguinte, existem unicamente em um mundo social; isto é, pelo homem e para o homem. (grifos do autor)

$\mathrm{O}$ autor se refere aos valores morais, que existem unicamente em atos ou produtos humanos e somente podem ser avaliados moralmente. A atribuição de um valor moral a um ato se dá diretamente pelas consequências que afetam outros indivíduos, um grupo social ou a sociedade como um todo.

Salienta que tal avaliação é sempre atribuição de um valor por parte de um sujeito e de como este, ao se colocar diante do ato do outro, o aprova ou reprova.

Desta maneira, julga-o não em função do modo como lhe afeta pessoalmente, mas como afeta a outros ou à comunidade inteira. Mas o sujeito que expressa desta maneira a sua atitude em face de certos atos o faz enquanto ser social e não enquanto sujeito puramente individual [...] não é ato de um eu abstrato ou de uma consciência avaliadora

Pensar a Prática, Goiânia, v. 17, n. 3, p. 878-892, jul./set. 2014 
em geral, e sim o da consciência de um indivíduo que, por pertencer a um ser histórico e social, encontra-se arraigada no seu tempo e na sua comunidade (VAZQUEZ, 1985, p. 133).

A atitude sempre estará ligada a um julgamento com concepção de valor, atos considerados positivos ou não do ponto de vista moral. É necessário compreender que as ideias de bem e mal mudam historicamente em função da moral vigente em cada época. Há de se entender que o "bem" pode entrar em choque com os interesses pessoais ou de grupos que constituem as camadas sociais refletidas nas instâncias onde estes convivem, e o ambiente formador certamente é um deles.

Vazquez (1985, p. 152) lembra que o bem é considerado valor fundamental e uma aspiração comum dos homens em cada época e em cada sociedade. $\mathrm{O}$ bem refletido em atitudes só pode realmente se sustentar se ocorrer a harmonização e a superação dos interesses do individualismo egoísta frente aos da comunidade, cujo alcance se dá pela conjunção obrigatória dos interesses pessoais e os gerais, universais. Culmina ao defender que o bem "se verifica como uma contribuição do indivíduo - pela sua incorporação ativa - a uma causa comum: a transformação das condições sociais nas quais está baseada a infelicidade da maioria".

Associada aos valores e às atitudes anda a norma, "padrões de conduta compartilhados pelos membros de um grupo social" (SARABIA, 2000, p. 128). São expectativas quanto ao comportamento esperado, um comportamento moral, obrigatório e devido de acordo com a regra ou norma de ação que deve excluir ou evitar atos por ela proibidos. Essa obrigatoriedade moral impõe deveres ao sujeito: "Toda norma funda um dever [...] supõe que a obrigatoriedade moral inclui a liberdade de escolha e de ação do sujeito e que este deve aceitar como fundamentada e justificada a mesma obrigatoriedade" (VAZQUEZ, 1985, p. 153).

As normas seguem um processo evolutivo que nasce com a 'aceitação', submissão social impositiva com baixa compreensão às suas razões; cursa com a 'conformidade', já com reflexões e avaliações, onde ocorre um sujeitamento em função da posição, papel e comportamento esperado socialmente; e culmina com o processo de 'interiorização', por compreender sua necessidade aceitando as regras básicas de vida coletiva. A não interiorização significa a falta de concordância entre atitudes e o comportamento, o que pode desembocar em conflitos relacionais (SARABIA, 2000).

Sustentadas em Eiser (1989), apresentam-se as suposições básicas em relação às atitudes para melhor entendê-las e explicá-las diante do que

Pensar a Prática, Goiânia, v. 17, n. 3, p. 878-892, jul./set. 2014 
pode ocorrer na sua manutenção ou transformação dentro de um processo educativo.

As atitudes são experiências subjetivas internalizadas, que o indivíduo experimenta na sua consciência, embora os fatores que intervêm na sua formação sejam de caráter social ou externo ao indivíduo; as atitudes são experiências de uma coisa ou objeto, uma situação ou uma pessoa, que para gerar uma atitude deve existir uma referência a alguma coisa ou a alguém; as atitudes envolvem uma avaliação da coisa ou objeto, situação ou pessoa, que por meio de experiências será avaliada como agradável ou desagradável; as atitudes envolvem juízos de valor, sugerem certa organização das crenças, das reações ou da capacidade de crítica, não exaustiva nem sequer correta ou adequada, mas é a compreensão em dado momento e em certa situação concreta; as atitudes podem ser expressas através da linguagem verbal e não-verbal, como os gestos, os silêncios, a não-participação ou o afastamento de uma situação, etc., mas é inegável que, se não contássemos com a linguagem verbal, a nossa percepção e o nosso conhecimento das atitudes seriam muito prejudicados; as atitudes são transmitidas e necessitam de audiência para serem recebidas e entendidas por outros; as atitudes são previsíveis em relação à conduta social, e, embora uma pessoa tenha uma atitude clara e concreta em relação a algo ou a alguém, nem sempre pode ou escolhe atuar de acordo com ele, por não serem os únicos fatores que intervêm na tomada de decisão.

Essas suposições podem muito auxiliar os educadores na compreensão e desenvolvimento da atitude no decorrer do processo de ensino-aprendizagem, bem como justificar a reciprocidade advogada entre atitude, valor e norma. O educador deve perceber que, diante de suas atividades educativas, "o grau de envolvimento das pessoas com os objetivos, metas e projetos coletivos está diretamente relacionado com a maneira como os valores e as crenças são manejadas no contexto de trabalho [...]" (GRAMIGNA, 2002, p. 18). Portanto, a atitude - querer ser e querer agir em determinada direção - é a mola propulsora e o principal componente da competência, desencadeadora da seleção do saber e do saber fazer da formação.

\section{Considerações Finais}

O processo formador está imerso em valores sociais que inspiram o seu fazer calcados em juízos valorativos, conferindo-lhe um caráter que pode ser mais conservador ou mais transformador. Desta forma, os valores assumem o papel de sustentáculo de um projeto educativo e, ao serem definidos, dão sentido e orientam a formação não só das atitudes, mas também

Pensar a Prática, Goiânia, v. 17, n. 3, p. 878-892, jul./set. 2014 
são capazes de (re)significar as necessidades que emergem constantemente na transmissão/construção de conhecimentos e habilidades.

As atitudes, por sua vez, impregnam o processo formador, guiando a aprendizagem de qualquer tipo de conteúdo. No entanto, muitas vezes a formação não tem prestado atenção suficiente aos valores almejados e tão pouco às cotidianas avaliações subjetivas (valorações) de seus participantes, ou seja, às manifestações das atitudes.

Ao longo deste ensaio, procurou-se destacar que o educador deve compreender que não pode pretender que seus estudantes respondam igualmente aos valores atitudinais contidos em sua ação educativa. Ele deve observar e reconhecer as reações advindas das interpretações realizadas por cada estudante, frutos das diferenças que as mesmas provocam pela e na vivência, além de considerar as atitudes adquiridas e internalizadas anteriormente ao processo.

Dentro do que é próprio das modernas e complexas sociedades, o papel da formação não será em nada compatível com seus fins se não dotar os indivíduos, ao longo de sua existência, com a capacidade de interagir com diferentes pessoas e em diversificados ambientes, favorecendo o rompimento dos papéis tradicionalmente reconhecidos. Esses fatores pressionam os indivíduos à necessária modificação de suas atitudes e valores ajustando ou criando novas condutas comportamentais.

Outro aspecto ressaltado foi que a formação e seus responsáveis deverão levar em consideração o repertório de recursos pessoais no desiderato contributivo em relação ao desenvolvimento e à mudança de atitudes. Além do componente cognitivo e da habilidade, normalmente priorizados na formação, o componente da atitude necessita ser considerado, porque é desencadeador/mobilizador de ação, e é pela ação que a conduta se revela, se declara, materializando os valores comportamentais, atitudinais.

Em síntese, o sistema de valores representa uma parte importante da visão que os indivíduos têm de si próprios em relação ao mundo, justificando plenamente a sua ênfase no processo educacional, considerando também que aspectos incorporados como crenças e conhecimentos são relevantes e, simultaneamente, constituem um forte vínculo com as atitudes. Todos esses intervenientes estão presentes e em evidência na dinâmica educacional e devem ser bem compreendidos para melhor formar e transformar as atitudes. Firma-se, portanto, o papel qualificador da atitude como atributo à competência e balizador da ação educacional.

\section{ATTITUDE: ATRIBUTE TO COMPETENCE}

Pensar a Prática, Goiânia, v. 17, n. 3, p. 878-892, jul./set. 2014 


\begin{abstract}
The objective of this work was to broaden the understanding about the competence in the educational field from the qualifying role carried out by the dimension of attitude. Throughout its trajectory it defended that the skills are a social construction, therefore, are not neutral. Presented the theoretical and conceptual basis that support the competences and its implications in the curriculum organization, emphasizing the personal qualities as a foundation of knowledge mobilization. Firmed the qualifying role of attitude as an atribute to the competence and marker of educational action in order to reach a more harmonious and integral conjunction throughout formation.
\end{abstract}

Keywords: Attitude. Competence. Formation.

\title{
ACTITUD: ATRIBUTO LA COMPETENCIA
}

\section{Resumen}

El objetivo de este estudio fue ampliar la comprensión de las competencias en educación desde el papel desempeñado por el calificador ejercido por la dimensión actitud. A lo largo de su carrera defendió que las competencias son una construcción social, por lo tanto, no son neutrales. Presentado a los conocimientos teóricos y conceptuales que sustentan las competencias y sus implicaciones para el currículo, destacando las cualidades personales como fundamento de la movilización de los conocimientos. Confirmó el papel de la actitud como atributo calificador de la competencia y la acción educativa con el fin de lograr un conjunto más armónico e integral a lo largo de la formación.

Palabras-claves: Actitud. Competencia. Formación.

\section{Referências}

ALLAL, L. Aquisição e avaliação das competências em situação escolar. In: DOLZ, J.; OLLAGNIER, E. (Orgs.). O enigma da competência em educação. Porto Alegre: Artmed, p. 79-96, 2004.

BATISTA, P. M. F. Discursos sobre a competência - contributo para a (re)construção de um conceito de competência aplicável ao profissional do desporto. 2008. 590 f. Tese (Doutorado em Ciências do Desporto) - Faculdade de Deporto, Universidade do Porto, Porto, 2008.

BURGOYONE, J. Competency based approaches to management development. Lancaster: Centre for the Study of Management Learning, 1988. 
DACOREGGIO, M. S. Competências para o currículo do curso de formação de administradores: do normativo para o pedagógico. 2006. 275 f. Tese (Doutorado em Educação Física) - Centro de Desportos, Universidade Federal de Santa Catarina, Florianópolis, 2006.

DELUIZ, N. O modelo das competências profissionais no mundo do trabalho e na educação: implicações para o currículo. Boletim Técnico do SENAC, v. 27, n. 3, set./out. 2001. Disponível em: http://www.senac.br/conhecimento/bts-tudo.html. Acesso em: 15 jun. 2011.

DOLZ, J.; OLLAGNIER, E. (Orgs). O enigma da competência em educação. Porto Alegre: Artmed, 2004.

EISER. J. R. Psicologia social. Madrid: Ediciones Pirámide, 1989.

ESTEVES, M. Construção e desenvolvimento das competências profissionais dos professores. Sísifo/Revista de Ciências da Educação, Lisboa, n. 8, p. 37-48, 2009.

GRAMIGNA, M. R. Modelo de competências e gestão de talentos. São Paulo: Makron Books, 2002.

KRECH, D.; CRUTCHFIELD, R. S.; BALLACHEY, E. L. O indivíduo na sociedade. São Paulo: Pioneira, 1969.

FERREIRA, A. B. H. Dicionário Aurélio da Língua Portuguesa. Rio de Janeiro: Nova Fronteira, 2009.

FURTER, P. Educação e vida. Petrópolis: Vozes, 1972.

LE BOTERF, G. Desenvolvendo a competência dos profissionais. Porto Alegre: Artmed, 2003.

MATOS, Z. Para uma definição do conceito e dos pressupostos do desenvolvimento da competência pedagógica. Porto: Universidade do Porto, 1989.

PERRENOUD, P. Pedagogia diferenciada: das intenções à ação. Porto Alegre: Artmed, 1999. 
SARABIA, B. A aprendizagem e o ensino das atitudes. In: COLL, C. (Org.). Os conteúdos na reforma: ensino e aprendizagem de conceitos, procedimentos e atitudes. Porto Alegre: Artes Médicas, 2000.

SEVERINO, A. J. Filosofia. São Paulo: Cortez, 2001.

SILVA, S. A. I. Valores em educação: o problema da compreensão e da operacionalização dos valores na prática educativa. Petrópolis: Vozes, 1988.

VAZQUEZ, A. S. Ética. Rio de Janeiro: Civilização Brasileira, 1985.

ZABALA, A. A prática educativa: como ensinar. Porto Alegre: Artmed, 1998.

ZARIFIAN, P. Objetivo competência: por uma nova lógica. São Paulo: Atlas, 2001.

Recebido em: 06/09/2013

Revisado em: 08/10/2013

Aprovado em: 15/10/2013

Endereço para correspondência:

julio.rocha@ufsc.br

Júlio Cesar Schmitt Rocha

Universidade Federal de Santa Catarina, Departamento de Educação Física - Centro de Desportos.

Campus Universitario CDS Bloco III

Trindade

88400900 - Florianópolis, SC - Brasil

Pensar a Prática, Goiânia, v. 17, n. 3, p. 878-892, jul./set. 2014 